\title{
An Analysis of the Functional Effectiveness of the Automatic Stabilisers of Fiscal Policy in China
}

\author{
Huachun Wang, Lu Zhao, Xuan Zhang \\ School of Government, Beijing Normal University, Beijing, China \\ Email address: \\ huachunwang@bnu.edu.cn (Huachun Wang), zhaolujoy@qq.com (Lu Zhao),823082461@qq.com (Xuan Zhang)
}

\section{To cite this article:}

Huachun Wang, Lu Zhao, Xuan Zhang. An Analysis of the Functional Effectiveness of the Automatic Stabilisers of Fiscal Policy in China. International Journal of Economics, Finance and Management Sciences. Vol. 3, No. 5, 2015, pp. 616-622.

doi: 10.11648/j.ijefm.20150305.35

\begin{abstract}
Granger causality Wald test and impulse response analysis were employed to test the functional effectiveness of automatic stabilisers of fiscal policy in China, which revealed that the automatic stabilisers exhibited asymmetries in fiscal revenues and expenditures. In particular, automatic fiscal stabilisers reduced economic fluctuations in fiscal revenue during economic booming and recession. With respect to fiscal expenditures, increases and decreases in central fiscal expenditures occurred during times of economic decline and growth, respectively, and thereby exerted countercyclical smoothing effects on the macro-economy; by contrast, increases and decreases in local fiscal expenditures occurred in accordance with economic developments, amplifying economic expansions or recessions. These differences in spending patterns between central and local governments caused malfunctions in automatic stabilisers that were related to fiscal expenditures. Given the premise that the relationship between central and local fiscal approaches should be rationalised, the fiscal spending policies should focus on investments in the livelihood and improvements in the autonomy of budgetary decisions by local governments.
\end{abstract}

Keywords: Fiscal Policy, Automatic Stabilisers, Asymmetry

\section{Introduction}

Automatic stabilizers are traditionally associated with the taxes, transfers and government spending. The function of automatic stabilizers relies on the assumption that the gross domestic product (GDP) or income fluctuations can be greatly smoothed by the changes in taxes and transfers during the economic cycle. This logic is normally attributed to Keynesian models of the economic cycle and the simplest representation is the traditional textbook version of the 'Keynesian cross' (Samuelson and Nordhaus, 1988; Mankiw, 2011). The effectiveness of automatic stabilisers of fiscal policy is closely related to a country's financial system (Rotemberg, 2003). The function of automatic stabilisers depends on the assumptions that a comprehensive system of public finance has been implemented in an economy and that government spending is designed to remedy market failures. It is also presumed that this spending primarily relates to public education, social security, and other social concerns. Under these conditions, fiscal expenditures should exhibit counter-cyclical characteristics (Stockman, 2001; Martin and Matteo, 2005).
The function of automatic stabilisers of fiscal policy will be reflected in fiscal surpluses or deficits (Mankiw, 2011). During economic expansions, fiscal revenues will surpass fiscal spending, producing fiscal surpluses that are likely to continue to rise throughout the course of each expansion. In particular, due to the progressive nature of the income tax system, if the economy is overheating, this increase in personal incomes and business profits will cause taxable entities to shift into higher tax brackets. This increased tax burden for individuals and businesses can inhibit investment and consumption demand, reduce macroeconomic volatility, and mitigate economic overheating (Yu and Cong, 2003). During economic recessions, income tax revenues decrease, whereas the persistent nature of fiscal expenditures causes governmental spending to increase rather than decline; these phenomena lead to budget deficits that are likely to rise throughout the course of each recession, enabling the economy to automatically maintain conditions of balanced growth (Li and Zhou, 2007).

International experience has revealed that there is a tremendous difference in the functional effectiveness of the automatic stabilisers of fiscal policy among different countries (Stockman, 2001). Some scholars believe that due 
to the lack of discretionary constraints will lead to fluctuations; the macro-control should be used automatic stabilizers as the only mechanism to achieve economic stability (Fatas and Mihov, 2003). Some scholars believe that discretionary interventions may be more competent than automatic stabilizers when the economy faces continuing large external shocks (Jia, 2008). However, the functions of automatic stabilizers were challenged in practice because they have not help those countries to achieve the goals of economic stability, whose fiscal policy showed significant pro-cyclical characteristics (Li and Zhou, 2007; Zhao and Li, 2002).

There are some attempts to provide a theoretical analysis of automatic stabilizers in stochastic dynamic general equilibrium models (Gali, 1994), they analysis different effects of government size in the context of a real business cycle model with flexible prices and continuous market clearing. The function of automatic stabilizers of fiscal policy is effective, but exist delay pro-cyclical characteristics (Arteta, et al., 2001). The effects of automatic stabilizers in the US economy during the post-war period was discussed and the automatic stabilizers functioned well (DeLong and Summers, 1986). Furthermore, the empirical analysis of federal tax system during 1962-1995 shows that the federal tax system offset about $8 \%$ of GDP initial impact (Auerbach and Hassett, 2002). Automatic stabilizers can be achieved through a budget that is zero on average, but the responsiveness of transfers and taxes is associated to the size of the budget (Fatás and Mihov, 2003).

Although the automatic stabilizers can play a role in the regulation of spontaneous, economic fluctuations, they can not completely eliminate economic fluctuations, and it will lead to greater economic fluctuations even in some cases (Hanson, 2004; Hess, et al., 2007). Confronted with the impact of the U.S. subprime mortgage crisis, the Chinese government implemented the proactive fiscal policy. However, the effect is inconsistent with the purpose of the anti-crisis (Chen, 2010). Automatic stabilizers alone can not be qualified for the role of stabilizing the economy due to the deficiencies in the system of the endogenous (Chen, 2010; Li and Zhou, 2007).

Why there exit different views on the functions of the automatic stabilizers? Do the function as the theory says? This article will adopt the theory of empirical and normative analysis, investigate the function of the automatic stabilizers in China. Chinese economic data after China implemented tax system reforms in 1994 were used to examine the functions that automatic stabilisers of fiscal policy, to test and analyse the effectiveness of the stabilisers. This article is organized as follows: We follow Keynesian approach and investigate the correlation of the automatic stabilizers of fiscal policy between economic booming and recession in China since the socialist market economy system target settled; to analyze the stability of the automatic stabilizers; followed by detection function of the automatic stabilizers of fiscal policy in China since 1992; then, analysis the characteristics and reasons of automatic stabilizers of Chinese fiscal policy; the final part summarizing the conclusions of this study, policy implications are discussed.

\section{The Asymmetric Effectiveness of Automatic Stabilizers of Fiscal Policy in China}

China has attained fiscal surpluses in certain fiscal years since tax system reformed in 1994, such as 2007, but has incurred fiscal deficits more often than not. China's economic growth rate was 9.8\% between 1994 and 2012 . Budget deficits are reasonable during economic recessions. In 1998, the Chinese economy underwent deflation due to the Asian financial crisis. During that time, the size of budget deficits relative to GDP continued to rise, increasing aggregate demand and stimulating economic growth; thus, automatic stabilisers of fiscal policy successfully fulfilled their role. Economic expansions occurred from 1994 to 1997 and from 2002 to 2008. According to the underlying principles of automatic stabilisers of fiscal policy, fiscal surpluses should occur during the above periods; however, budget deficits frequently occurred during economic expansions. This phenomenon is inconsistent with the fundamental tenets regarding automatic stabilisers; as a result, the role of these automatic stabilisers of fiscal policy in China has been challenged (see Figure 1).

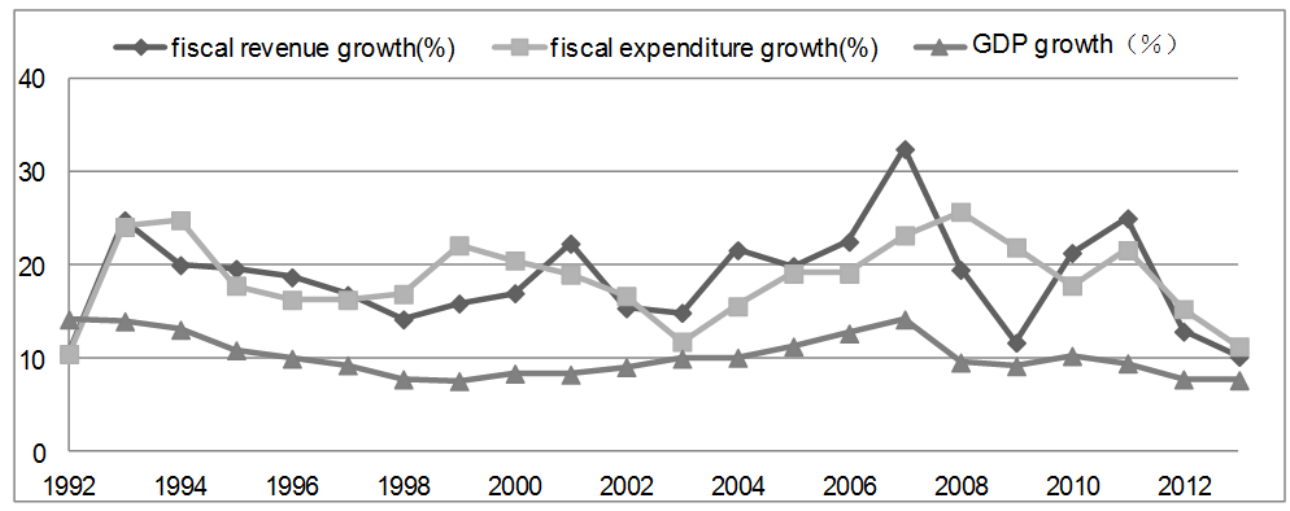

Source: NSB (1992-2014).

Figure 1. GDP growth and increase in fiscal revenue and expenditure changes from 1992 to 2013. 
Since China's implementation of tax system reforms, Chinese budgetary deficits have risen during economic recessions, indicating that the automatic stabilisers of fiscal policy have functioned during these times. However, periods of economic prosperity and rapid growth have not been accompanied by the emergence and expansion of fiscal surpluses; instead, persistent fiscal deficits have occurred during these periods, indicating general malfunctions in the automatic stabilisers of fiscal policy. These phenomena indicate that automatic stabilisers of fiscal policy in China are only halfway effective; moreover, the functional effectiveness of these stabilisers is asymmetric. These issues may be caused either by fiscal revenues or fiscal expenditures; alternatively, these problems could result from the combined effects of fiscal revenues and fiscal expenditures.

The procyclical characteristics of fiscal revenues partly leads to automatic stabilizers halfway effective. Analyses of the examined data from the perspective of fiscal revenue revealed that fiscal revenue and economic growth trends tended to exhibit similarities; in other words, during economic expansions, fiscal revenues increased, automatically restraining tendencies towards economic overheating. During economic recessions, fiscal revenues decreased, reducing the tax burdens of businesses and individuals; this effect promoted investment and consumption, automatically acting to prevent the economy from sliding further into recession. This pattern of variation in fiscal revenues relative to economic growth suggested that fiscal revenues exhibited procyclical characteristics that are in accordance with the intended function of automatic stabilisers of fiscal policy.

According to statistical analysis of the Chinese case, China began a new economic cycle in 1992. After the implementation of tax reform in 1994, fiscal revenue increased by $20 \%$. In 2007 , GDP and fiscal revenue grew by $14.2 \%$ and $32.4 \%$, respectively. Although GDP growth and fiscal revenue increases peaked at different times, both of these phenomena exhibited similar characteristics during the process of attaining their peak values. In particular, during economic expansions, economic growth was accompanied by rising fiscal revenue; thus, increases in economic growth and fiscal revenue occurred in synchronised fashion (see Figure 1).

In recent decades, the Chinese economy has entered recessions due to the financial crisis in Asia in 1998 and the U.S. subprime mortgage crisis in 2008; during these recessionary periods, China's fiscal revenue growth sharply declined. In 1998, China's fiscal revenues increased by $14.2 \%$, which was the lowest level of annual fiscal revenue growth between 1994 and 2008. In 2009, fiscal revenue increased by only $11.7 \%$; this increase was the lowest level of fiscal revenue growth that had occurred in nearly a decade. The downward trend of fiscal revenue growth during the aforementioned two occasions was consistent with the declining trends in economic growth. In other words, economic recessions were accompanied by declines in revenue growth; thus, economic downturns and declines in fiscal revenues were synchronised (see Figure 1).

In addition to statistical and qualitative analyses, to objectively reflect the relationship between fiscal revenues and economic growth, the vector autoregression (VAR) approach was utilised to conduct dynamic quantitative analyses of fiscal revenue and GDP (Gabriel, et al., 2010). In the VAR model, increases in fiscal revenue and GDP growth were denoted by fiscal_inc and gdp, respectively. The relevant data were first subjected to a stability test; the test results indicated that both GDP growth and increases in fiscal revenue were stationary time series that were suitable for the application of a Granger causality test to explore the relationship between these two variables (see Table 1).

Table 1. Variables stationary test.

\begin{tabular}{lllll}
\hline & DF test & ADF test \\
\hline \multirow{2}{*}{ Variables } & Test & $\mathbf{5 \%}$ & Test & $\mathbf{5 \%}$ \\
& Statistic & CriticalValue & Statistic & CriticalValue \\
\hline Gdp & -2.638 & -2.980 & -3.698 & -2.989 \\
Fiscal & -2.674 & -2.980 & -3.068 & -2.983 \\
\hline
\end{tabular}

Note: The data show that the DF test variables gap and fiscal may refuse the existence of the unit root null hypothesis at the 5\% significance level. Autocorrelation disturbance term that may exist due to the DF test. The test results show that the original assumptions of variable gdp and fiscal significance may be refused unit root at the level of $5 \%$. Therefore, both GDP growth and fiscal revenue growth variables are stationary time series, which can be directly used for quantitative analysis.

According to the measurement results, the null hypothesis that economic growth rates (gdp) were not the Granger cause of fiscal revenue increases (fiscal_inc) was rejected at the $2.67 \%$ level, indicating that economic growth has an impact on fiscal revenues and that fiscal revenue fluctuations occur as a result of economic growth. By contrast, the null hypothesis that financial revenue increases (fiscal_inc) do not Granger cause economic growth rates (gdp) was accepted at a $5 \%$ probability level. These results indicate that changes in fiscal revenue growth lag behind changes in economic growth; in other words, declines in economic growth are followed by decreases in fiscal revenue (see Table 2).

Table 2. Granger causality Wald test.

\begin{tabular}{lllll}
\hline Equation & Excluded & chi2 & df & Prob $>$ chi2 \\
\hline gdp & Fiscal & 0.69262 & 2 & 0.707 \\
fiscal & Gdp & 2.0264 & 2 & 0.363 \\
\hline
\end{tabular}

Note: Related variables are stationary sequence, Granger causality test can be used to discover the dynamic relationship. The results show that the $\mathrm{p}$-value is greater than 0.05 , therefore, both gdp and fiscal explanatory variables are non-causality.

Impulse response analysis was employed to determine whether economic growth and the increases in fiscal revenue were procyclical or countercyclical. In the VAR model, if the 
variance-covariance matrix of the disturbance terms in the model estimation equation is not diagonal, then the orthogonalisation of this matrix is required. In this study, the generalised impulse response function (GIRF) was used to analyse the impulse response relationship, and the results of this analysis revealed that an impulse response relationship existed between the rate of economic growth and increase in fiscal revenue, indicating that increases in financial revenues and economic growth may be associated (Taylor, 2000). Although lags between these two phenomena negatively impacted this relationship, on the whole, a significant positive relationship existed between economic growth rates and fiscal revenues, indicating that fiscal revenues exhibited procyclical characteristics (see Figure 1).

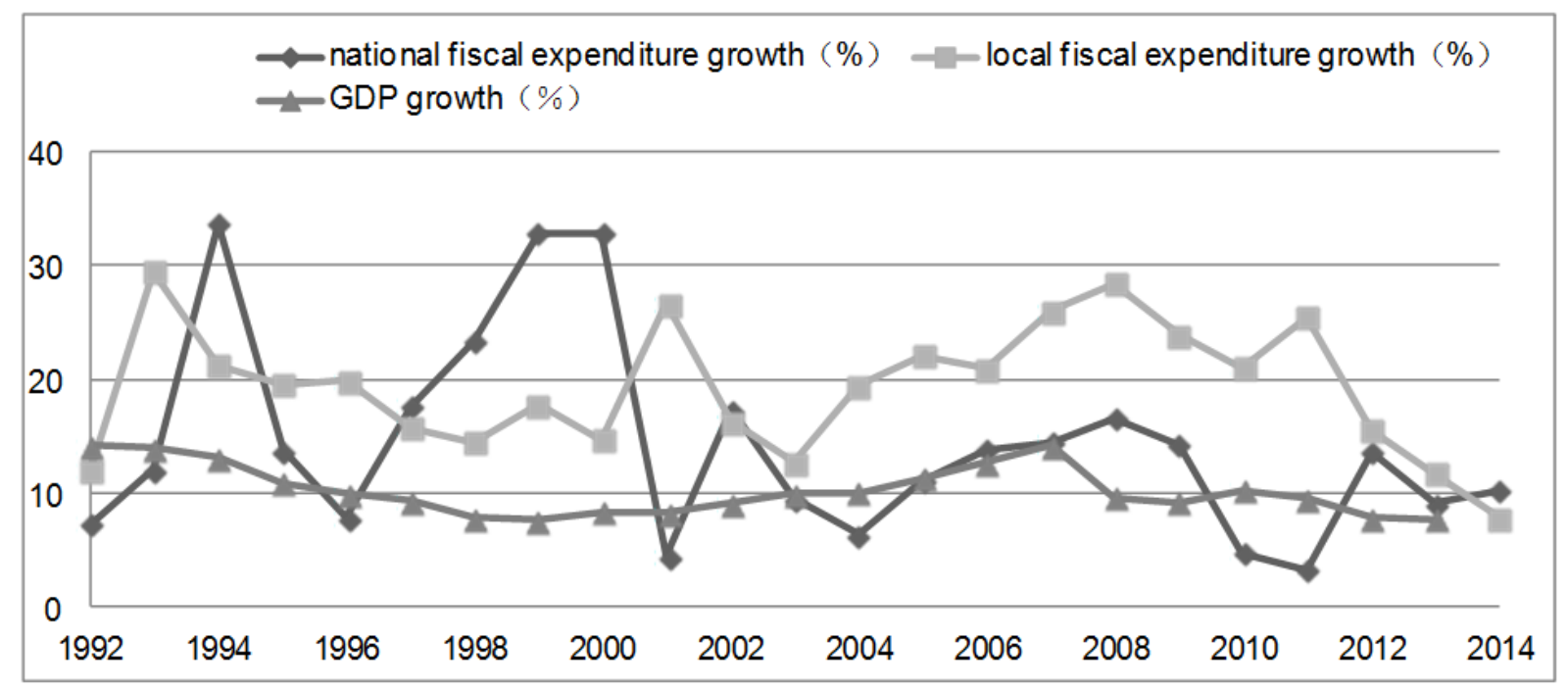

Source: NSB (1992-2014).

Figure 2. Changes of GDP growth, local and national fiscal expenditure from 1992 to 2014.

The above analyses determined that in China, changes in economic growth and in fiscal revenue were synchronised. This result established that China's fiscal revenues demonstrated procyclical traits with respect to economic growth and that changes in fiscal revenue occurred in accordance with the expected functions and characteristics of automatic stabilisers of fiscal policy.

\section{Causes of Asymmetry: Differences in Central and Local Fiscal Expenditures}

The preceding analyses established that fiscal revenues served as an internal automatic stabiliser of economic growth in China; however, this result raises the question of why automatic stabilisers have proven to be ineffective in curbing economic overheating and sharp economic downturns. Next the study begins to test the hypothesis that this ineffectiveness has occurred because of structural differences between China's central and local fiscal expenditures. China has not yet established a public finance system; to a large extent, government funds are allocated to various purposes, such as investment, production, and other economic activities, that should be pursued by the private sector (Yu and Cong, 2003). During economic expansions, local governments have often found it difficult to restrain impulses to engage in investment. As a result, although fiscal spending should theoretically decrease during economic expansion, in actuality, local fiscal spending continued to increase, promoting economic overheating. Moreover, local governments could not issue debt during economic downturns and were therefore powerless to affect economic recessions.

Statistical data reveal that since 1994, although China has maintained a high level of GDP growth, its long-term increases in fiscal spending have outstripped its rate of GDP growth. In particular, data reveal that even during economic overheating, fiscal spending increases continued to rise. For example, in 1994, China's fiscal spending increased by $24.8 \%$. In 2007, fiscal revenue reached 5.1 trillion yuan, which was 700 billion yuan greater than its budget. This increase in fiscal revenue suggested economic overheating; however, during the same year, the central budget deficit reached 200 billion yuan, and fiscal expenditures increased by $23.2 \%$. The central budget deficit that has occurred in nearly every year since 1995 reflects the inconsistency between fiscal expenditures and the inherent requirements for the function of automatic stabilisers.

The failures in the function of the automatic stabilisers of China's fiscal spending may be partially attributed to institutional design. Chinese local governments implement balanced budgets, and only the central government can issue debt. Thus, increases or decreases in central fiscal spending may oppose the direction of economic growth, but to achieve a balanced budget, local governments must equalise their fiscal revenues and expenditures. Under conditions in which local fiscal revenue is directly related to the economic cycle, local fiscal expenditures must also be synchronised with the economic cycle, rendering it difficult for automatic fiscal stabilisers to function effectively. If the total local fiscal spending is greater than the total central fiscal spending, the 
procyclical nature of local fiscal spending will lead to failures in the functions of these automatic stabilisers.

The trends of fluctuations in central and local fiscal spending in China demonstrate significant differences. In particular, during the 1998 financial crisis in Asia and the 2008 economic downturn that was triggered by the U.S. subprime mortgage crisis, the growth rate for central fiscal spending was greater than the economic growth rate; this growth in expenditures stimulated the economy. During economic expansions, the growth of central fiscal expenditures decreased, contributing to the cooling of the Chinese economy (see Figure 3).

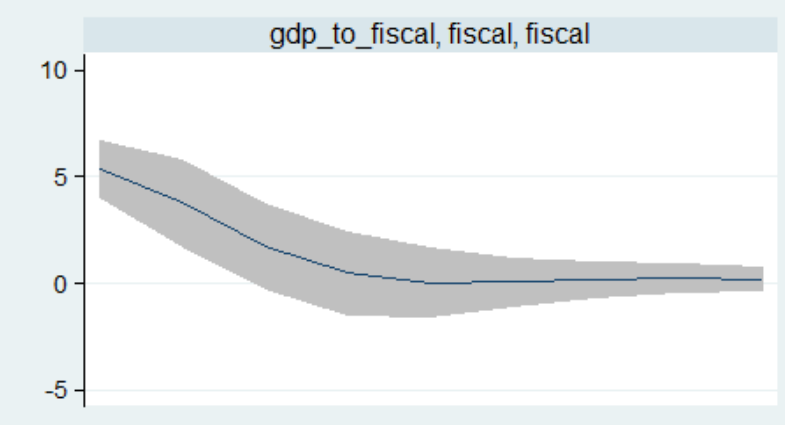

gdp_to_fiscal, gdp, fiscal

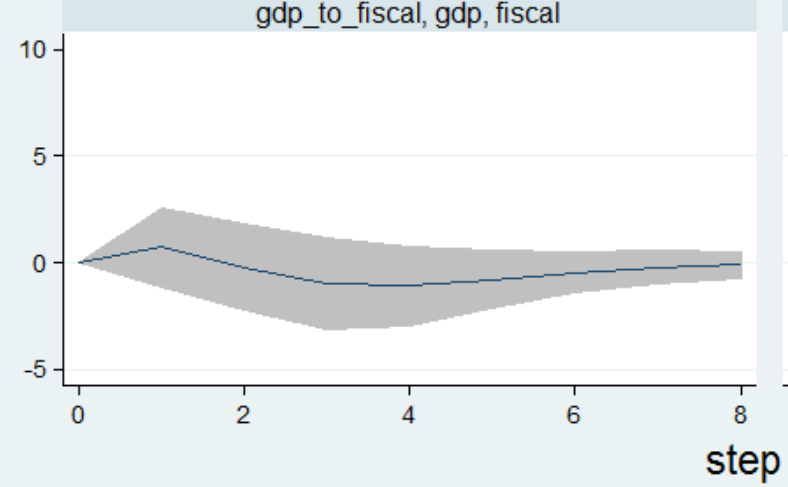

$95 \% \mathrm{Cl}$ gdp_to_fiscal, fiscal, gdp

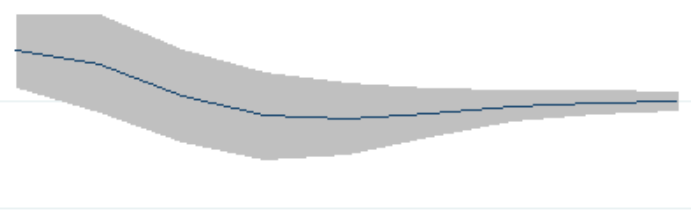

gdp_to_fiscal, gdp, gdp

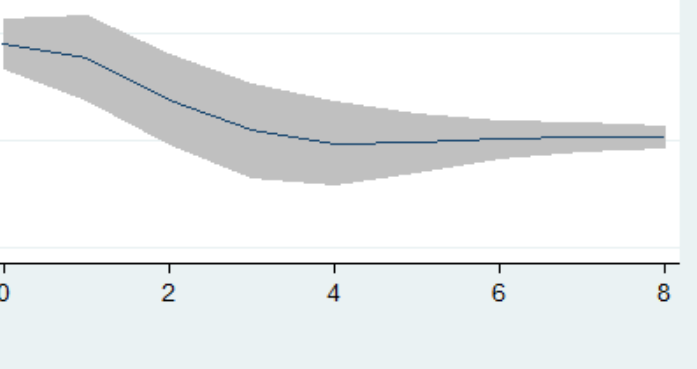

orthogonalized irf

Graphs by irfname, impulse variable, and response variable

Figure 3. Fiscal revenue growth and the pulse response from the economic growth.

This study then used GIRF to measure the relationship between the changes in GDP and fiscal expenditures. The results from this assessment revealed that positive fluctuations in the economic growth rate would be accompanied by greater increases in fiscal expenditures. Although lags in increases in fiscal expenditures led to negative changes in economic growth, the cumulative effect was positive, indicating that fiscal spending was procyclical with respect to economic growth; as a result, the function of automatic stabilisers failed in terms of fiscal expenditures (see Table 2).

To objectively assess the function of the automatic stabilisers of central fiscal spending, this paper quantitatively examined central fiscal expenditures and economic growth rates in China. The results of this assessment revealed that there was no unit root for the relevant variables. Statistical analysis using the GIRF of the VAR model revealed a negative cumulative impulse response of increases in central fiscal spending to economic growth rates, indicating a countercyclical relationship between central fiscal expenditures and economic growth; thus, automatic stabilisers functioned with respect to central fiscal spending.
By contrast, local fiscal spending appeared to be procyclical with respect to economic growth during the examined time period, and this trait of local fiscal expenditures caused malfunctions in automatic stabiliser effects.

In summary, because the magnitude of increases in central fiscal expenditures was lower during economic expansions than during economic recessions, the countercyclical characteristics of these central fiscal expenditures exerted a significant effect in curbing economic recessions. During economic expansions, the economy-cooling effect of decreases in central fiscal expenditures is offset by increases in local fiscal expenditures; therefore, local fiscal expenditures have a role in fuelling economic expansions, and overall national fiscal expenditures produce asymmetric effects on economic expansions and economic recessions.

\section{Conclusions and Policy Implications}

Chinese fiscal revenues exhibit procyclical characteristics, increasing and decreasing during economic expansions and economic recessions, respectively. Thus, these revenues 
appear to function as automatic stabilisers of fiscal policy that reduce economic volatility. However, increases in fiscal spending during economic expansions exacerbate the risk of economic overheating and cause automatic fiscal stabilisers to malfunction. Malfunctions of the automatic stabilisers of fiscal policy produce adverse effects on steady macroeconomic growth and render it difficult to achieve a balanced budget in each fiscal cycle. As the basic regulatory mechanisms to stabilize the economy, it is important to gradually increase the sensitivity of the automatic stabilizers on the changes in the economic cycle. There exists a need to deepen the reforms to the current public finance system in various ways, including the following measures.

(1) The tilting of fiscal spending towards the livelihood of the people. The current direction of fiscal spending should be reformed to focus on the livelihood of the people, improvements to the social security system, and the establishment of a financial management system that incorporates robust automatic stabilisers of fiscal policy.

(2) Improvements to the autonomy of local governments with respect to their budgets. Local fiscal budgets should be required to balance their fiscal revenues and expenditures over the course of economic cycles rather than in each fiscal year. Situations in which high revenues are coupled with high spending and low revenues are coupled with low spending should be avoided in local fiscal budgets. Local governments should be allowed to achieve cyclical budget balance. In the long term, the issuance of debt by local governments produces a countercyclical effect that allows the automatic stabilisers of local fiscal policy to function.

(3) Reasonable control of the issuance of government bonds. The central Chinese government should optimise the maturity structure of government bonds and appropriately increase the proportion of long-term bonds in this structure. This process would allow the government to not only meet the needs of public investment but also delay the debt burdens of government finances. Moreover, the Chinese government must establish an improved regulatory system for government bonds and assets and increase the efficiency of its use of funds acquired through government bonds.

(4) The optimisation of the structure and scope of public financing. Improvements in public financing would require government capital to gradually exit from competitive industries and shift to investments in public domains, such as infrastructure construction and environmental protection. Public financing should expand the supply of public goods, form a complementary relationship with private capital, reduce the costs and risks of private investment, and increase the marginal rate of return of private investments, thereby stimulating the growth of these private investments.

\section{Acknowledgement}

We would like to thank the Co-construction of Public Administration Program in Beijing for financial support. Thank Liu Qingjie, Ph.D candidate, for the help during the preparation of this paper.

\section{References}

[1] Auerbach, Alan and Hassett, Kevin, 2002, "Fiscal Policy and Uncertainty", International Finance, Vol. 5, No. 2, pp. 229249.

[2] Fatás, Antonio and Mihov, Ilian, 2003, "The Case for Restricting Fiscal Policy Discretion", Quarterly Journal of Economics, Vol. 118, No. 4, pp.1419-1447.

[3] DeLong, Bradford and Summers, Lawrence, 1986, "Is Increased Price Flexibility Stabilizing?" American Economic Review, Vol. 76, NO.5, pp 1031-1044. Available at: http://works.bepress.com/brad_delong/11.

[4] Arteta, Carlos and Barry, Eichengreen, and Charles, Wyplosz, 2001, "When does capital account liberalization help more than it hurts?" Working paper 8414, http://www.nber.org/papers/w8414.

[5] Chen, Jianqi, 2010, "How the fiscal stability failed?", Government Finance, Vol. 24, No. 10, pp. 26-27.

[6] Gabriel, Cuadra and Juan, Sanchezb, and Horacio Saprizac, 2010, "Fiscal policy and default risk in emerging markets," Review of Economic Dynamics, Vol. 13, No. 2, pp. 452-469.

[7] Gali, Jordi, 1994, "Government size and macroeconomic stability”, European Economic Review, Vol. 38, No. 1, pp. 117-132.

[8] Hanson, Michael, 2004, The 'Price Puzzle' Reconsidered, Journal of Monetary Economics, Vol. 51, No. 7, 1385-1413.

[9] Ernesto, Talvi and Vegh, Carlos, 2005, "Tax base variability and procyclical fiscal policy", Journal of Development Economics, Vol. 78, No., 156-190.

[10] Hess, Chung and Troy, Davig, and Eric Leeper, 2007, "Monetary and Fiscal Policy Switching", Journal of Money, Credit and Banking, Vol. 39, No. 4, pp. 809-842.

[11] Jia, Kang, 2008, "The proactive fiscal policy and a prudent fiscal policy-the road to public finance construction," Journal of Tongling College, Vol. 19, No. 1, pp.4-11.

[12] Li, Yongyou and Zhou, Dajun, 2007, “Automatic stabilizer vs. discretion: weighing and perfecting on macro-control mechanism of fiscal policy," Finance \& Trade Economics, Vol. 18, No. 2, pp. 10-18.

[13] Mankiw, Gregory, 2011, Principles of macroeconomics (Fifth edition), McGraw-Hill, pp. 458-462.

[14] Martin, Larch and Matteo, Salto, 2005, "Fiscal rules, inertia and discretionary fiscal policy," Applied Economics, Vol. 37, No.10, pp. 1135-1146.

[15] NBS (National Bureau Statistics of China), 1992-2012, China Statistical Yearbook, Bureau of Statistics. Beijing: China Statistical Press.

[16] Rotemberg, Julio, 2003, "Stochastic technical progress, smooth trends, and nearly distinct business cycles," American Economic Review, Vol. 93, No. 5, pp. 1543-1559.

[17] Samuelson, Paul and Nordhaus, William, Economics, MaGram-Hill (Sixteenth edition), 1998. pp 459-462.

[18] Stockman, David, 2001, "Balanced-budget rules: welfare loss and optimal policies", Review of Economic Dynamics, Vol. 4, No. 2, pp. 438-459. 
[19] Taylor, John, 2000, "Reassessing discretionary fiscal policy," Journal of Economic Perspectives, Vol. 14, No.3, $\mathrm{pp} \cdot 21-36$.

[20] Yu, Yongding and Cong, Liang, "Financial functions and stages of economic development in China," Chinese Social Sciences Today, 2003-05-08, third edition.
[21] Zhao, Hongmei and Li, Jinxia, 2002, "Schools of western economics," China Financial and Economic Publishing House, Beijing, pp. 8-14. 